\title{
Hippocampal cells have mnemonic correlates as well as spatial ones
}

\author{
DAVID S. OLTON, CYNTHIA G. WIBLE, and KEVIN PANG \\ Johns Hopkins University, Baltimore, Maryland \\ and \\ YOSHIO SAKURAI \\ Toyama Medical and Pharmaceutical University, Toyama-shi, Japan
}

\begin{abstract}
The activity of complex spike cells in the hippocampus is strongly correlated with the location of a rat in a spatial environment. These results have led to the development of the cognitive mapping theory of hippocampal function. However, a considerable body of evidence from experiments examining the behavioral changes following lesions of the hippocampus emphasizes its role in memory (both spatial and nonspatial), rather than cognitive mapping. If the hippocampus plays a role in nonspatial mnemonic processes as well as in cognitive mapping, then the activity of complex spike cells in the hippocampus ought to be correlated with different types of mnemonic demands. In this article, we review the results from relevant experiments, which indicate that complex spike cells do have mnemonic correlates in some behavioral tasks. These results suggest that current theoretical interpretations of hippocampal function should emphasize both mnemonic and cognitive mapping processes.
\end{abstract}

Many different theoretical frameworks have been used to explain hippocampal function. The experiments described here were designed to address the interrelationship of two different approaches. The cognitive mapping analysis of hippocampal function emphasizes its role in spatial behaviors, and was developed primarily as a result of experiments demonstrating spatial correlates of complex spike cells in the hippocampus (Leonard \& McNaughton, in press; Muller, Kubie, \& Ranck, 1987; O'Keefe \& Nadel, 1978; Olton, in press-c). The mnemonic interpretation of hippocampal function emphasizes its role in processing certain types of memory, defined on the basis of the associative characteristics of that memory, rather than the spatial or nonspatial nature of the stimuli that are to be remembered. It was developed primarily as a result of experiments showing substantial and circumscribed impairments of memory following lesions of the hippocampus (Corkin, 1984; Olton, 1983, in press-b; Rawlins, 1985; Squire, 1987; Zola-Morgan, Squire, \& Amaral, 1986).

Some initial attempts to examine the relative merits of these two approaches set them up as mutually exclusive alternatives. For example, if the hippocampus has a selective spatial function, then cellular activity in it should not be correlated with nonspatial, mnemonic processes. On the other hand, if the hippocampus has only nonspatial mnemonic functions, then cellular activity should be cor-

Cynthia G. Wible is currently at Wellesley College, Wellesley, MA. Correspondence may be addressed to David S. Olton, Neuromnemonics Laboratory, Department of Psychology, Johns Hopkins University, Baltimore, MD 21218. related with the appropriate mnemonic processes regardless of the nonspatial characteristics of the stimuli and responses.

Lesions of the hippocampus consistently impair performance in tasks that require recent memory, a type of memory that is necessary to perform accurately in any type of delayed conditional discrimination (DCD; see reviews in O'Keefe \& Nadel, 1978; Olton, 1983). At the beginning of each trial in a DCD, one or more stimuli are presented to the individual. The stimuli are then removed for a delay. At the end of the delay, two or more responses are available. The response that is correct is conditional on the stimuli presented at the beginning of the trial. Lesions of the hippocampus produce impairments in many different types of DCDs-either a main effect (so that choice accuracy is reduced at all delays), or an interaction (so that choice accuracy is reduced to a greater extent at longer than at shorter delays). These impairments occur for both spatial and nonspatial discriminative stimuli (see review in Raffaele \& Olton, 1988).

Because the results of lesion studies have demonstrated that the hippocampus is required for normal choice accuracy in DCDs, these tasks provide an excellent opportunity to determine if hippocampal cells have mnemonic correlates, that is, activity associated with the mnemonic demands of the task. In one experiment, a visual DCD was used (Wible et al.,1986). The discriminative stimuli were two goalboxes, which differed in brightness. At the beginning of each trial, for the sample phase, one goalbox was blocked and the rat entered the other goalbox to obtain reinforcement (a sucrose solution). For the delay, the rat was returned to the start area. For the choice 
phase, the block was removed so that the rat could enter either goalbox. However, only the goalbox that was entered during the sample phase had reinforcement in it (delayed match-to-sample). Activity was recorded from single units while the rat was in the goalbox drinking sucrose, a situation in which both the stimuli and the responses were highly controlled.

In some units, activity was differentially associated with the phase of the task (sample phase or choice phase). For these units, the stimuli (in the goalbox) and the responses (drinking the sucrose) were identical during the period of recording in both runs. Consequently, the differential unit activity had to reflect the difference in the mnemonic characteristics of the two runs (acquisition of information during the sample phase, retrieval and use of that information during the choice phase). In other units, activity was differentially correlated with the nonspatial, discriminative stimuli. These units fired differentially in the presence of one goalbox as compared to the other. The nonspatial correlates were presumably elicited by the fact that these stimuli were involved in the DCD.

Finally, in many units, activity was correlated with the interaction of two or more variables. For example, unit activity increased in the presence of a particular discriminative stimulus (black or white compartment) and a particular phase (sample or choice phase). These correlates with an interaction of two or more relevant mnemonic dimensions were also characteristic of units recorded in monkeys performing in a DCD task (Watanabe \& Niki, 1985).

Continuous nonmatch-to-sample (CNM) also showed significant mnemonic correlates of single units in the hippocampus (Sakurai, 1988). CNM is a form of a DCD because the correct response for each stimulus depends upon a comparison of that stimulus with the immediately preceding one. A go/no-go stimulus-response-reinforcement contingency was in effect; a go response was correct on nonmatch trials (a change in stimuli), a no-go response was correct on match trials (a repetition of the stimulus from the preceding trial).

Single cells were recorded in many different areas of the hippocampus. In many of the cells, mnemonic correlates were associated with behavior in the task. For example, the activity of many cells in CA1 and CA3, in response to the onset of the stimulus, was greater on nonmatch (go) trials than on match (no-go) trials. For both of these types of trials, the stimuli were identical, but the unit's response was different because of changes in mnemonic variables.

Much remains to be accomplished in the analysis of mnemonic correlates of hippocampal unit activity. Psychological analyses (Olton, in press-a) must identify the kinds of memory that elicit mnemonic correlates in hippocampal units. Neurophysiological analyses must identify the ways in which different components of the hippocampal system process this mnemonic information, and must describe the transformations that signals undergo as they are transduced from one neuron to another along the chain of receptors, interneurons, and effectors. Nonethe- less, these data provide strong evidence that single-unit activity in the hippocampus does have mnemonic as well as spatial correlates.

Consequently, the original phrasing of the question about the relative merits of spatial and mnemonic analyses of hippocampal function was probably incorrect. Is the hippocampus a spatial or a mnemonic processor? The answer is clearly yes. Comparison of these two approaches might proceed best if the question was changed, perhaps to: "How does the hippocampus process both spatial and nonspatial, mnemonic information?' This alternative approach is not meant to blur the distinction between spatial and nonspatial analyses, nor to imply that either of these analyses is already complete in itself; both of them have much to accomplish individually. However, each analysis might benefit by considering the results obtained by the other, and the best neurocomputational analyses of hippocampal function will obviously be able to incorporate them both.

\section{REFERENCES}

Corkin, S. (1984). Lasting consequences of bilateral medial temporal lobectomy: Clinical course and experimental findings in H.M. Seminars in Neurology, 4, 249-259.

LeONARD, B. J., McNaughton, B. L. (in press). Spatial representation in the rat: Conceptual, behavioral, and neurophysiological perspectives. In D. S. Olton \& R. Kesner (Eds.), The neurobiology of comparative cognition. Hillsdale, NJ: Erlbaum.

Muller, R. U., Kubie, J. L., \& RANCK, J. B., JR. (1987). Spatial firing patterns of hippocampal complex-spike cells in a fixed environment. Journal of Neuroscience, 7, 1935-1950.

O'KEEFE, J., \& NADEL, L. (1978). The hippocampus as a cognitive map. Oxford: Clarendon University Press.

OLton, D. S. (1983). Memory functions and the hippocampus. In W. Seifert (Ed.), Neurobiology of the hippocampus (pp. 355-373). New York: Academic Press.

OLton, D. S. (in press-a). Dimensional mnemonics. In G. H. Bower (Ed.), The psychology of learning and motivation (Vol. 23). New York: Academic Press.

OLton, D. S. (in press-b). Mnemonic functions of the hippocampus: Single unit analyses in rats. In V. Chan-Palay \& C. Köhler (Eds.), The hippocampus: New vistas. New York: Liss.

OLton, D. S. (in press-c). Spatial perception: Behavioral and single unit analyses. In C. Stebbins \& M. A. Berkley (Eds.), Perception. New York: Plenum.

Raffaele, K. C., Olton, D. S. (1988). Hippocampal and amygdaloid involvement in working memory for nonspatial stimuli. Behavioral Neuroscience, 102, 349-355.

RAwlins, J. N. P. (1985). Association across time: The hippocampus as a temporary memory store. Behavioral \& Brain Sciences, 8 , 479-496.

SAKURAI, Y. (1988). Thalamocortical, hippocampal and auditory neuronal activities related to auditory working memory in the rat. Neuroscience Abstracts, 14, 862.

SQUIRE, L. R. (1987). Memory and brain. New York: Oxford University Press.

Watanabe, T., Nikı, H. (1985). Hippocampal unit activity and delayed response in the monkey. Brain Research, 325, 241-254.

Wible, C. G., Shapiro, M., Findung, R. L., Lang, E. J., Crane, S., * Olton, D. S. (1986). Mnemonic correlates of unit activity in the hippocampus. Experimental Brain Research, 399, 97-110.

Zola-Morgan, S., SQuire, L. R. A Amaral, D. G. (1986). Human amnesia and the medial temporal region: Enduring memory impairment following a bilateral lesion limited to field CAl of the hippocampus. Journal of Neuroscience, 6, 2950-2967. 